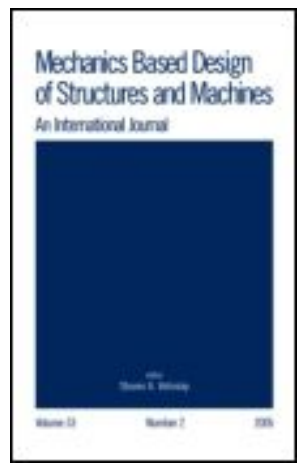

\title{
Influence of Carbon Nanotubes on Thermal Expansion Coefficient and Thermal Buckling of Polymer Composite Plates: Experimental and Numerical Investigations
}

\begin{tabular}{|r|l|}
\hline Journal: & $\begin{array}{l}\text { Mechanics Based Design of Structures and Machines, An International } \\
\text { Journal }\end{array}$ \\
\hline Manuscript ID & LMBD-2019-0174.R4 \\
\hline Manuscript Type: & Research Papers \\
\hline Author: & 25-Sep-2019 \\
\hline Complete List of Authors: & $\begin{array}{l}\text { Kamarian, S.; Amirkabir University of Technology } \\
\text { Bodaghi, Mahdi; Nottingham Trent University } \\
\text { Barbaz, Reza; Amirkabir University of Technology } \\
\text { Shakeri, Mahmoud; Amirkabir University of Technology } \\
\text { Yas, M. H.; Razi University }\end{array}$ \\
\hline Keywords: & $\begin{array}{l}\text { Multi-Walled Carbon Nanotubes, Nanocomposites, Experiments, } \\
\text { Coefficient of Thermal Expansion, Thermal Buckling }\end{array}$ \\
\hline
\end{tabular}

\section{SCHOLARONE Manuscripts}




\title{
Influence of Carbon Nanotubes on Thermal Expansion Coefficient and Thermal Buckling of Polymer Composite Plates: Experimental and Numerical Investigations
}

S. Kamarian ${ }^{a}{ }^{\dagger}$, M. Bodaghi ${ }^{\mathrm{b}}$, R. Barbaz Isfahani ${ }^{\mathrm{a}}$, M. Shakeria, M. H. Yas ${ }^{\mathrm{c}}$

\author{
a. Department of Mechanical Engineering, Amirkabir University of Technology, Tehran, Iran \\ b. Department of Engineering, School of Science and Technology, Nottingham Trent University, Nottingham, \\ NG11 8NS, United Kingdom \\ c. Department of Mechanical Engineering, Razi University, Kermanshah, Iran
}

† Corresponding Author, E-mail: kamarian.saeed@yahoo.com 


\begin{abstract}
The first aim of this paper is to experimentally explore the effect of multi-walled carbon nanotubes (MWCNTs) on the coefficient of thermal expansion (CTE) of epoxy-based composites. Focusing on the obtained experimental data, two important conclusions can be drawn. 1) Though the CTE of carbon nanotubes (CNTs) is lower than that of neat epoxy, using more CNT does not necessarily decrease the CTE of epoxy polymer. 2) The optimum weight percent of CNT is 0.3 which can reduce the CTE of epoxy up to $33 \%$. As the second goal of the present research work, thermal buckling analysis of rectangular carbon fiber-reinforced CNT/epoxy polymer (CFRCNTEP) laminated composite plates is performed numerically. To this purpose, first, using the obtained experimental data and micro-mechanical models, the thermo-elastic properties of structure are calculated. Then, based on the first-order shear deformation theory (FSDT) and by means of generalized differential quadrature (GDQ) method, the influence of CNTs on the critical buckling temperature of CFRCNTEP composite plates is investigated. The numerical results reveal that MWCNTs can strongly affect thermal buckling behavior of composite plates. It is observed that by adding $0.3 \mathrm{wt} \% \mathrm{CNTs}$ into the matrix phase, the critical buckling temperature increases between 35 to $42 \%$.
\end{abstract}

Keywords: Multi-Walled Carbon Nanotubes, Nanocomposites, Experiments, Coefficient of Thermal Expansion, Thermal Buckling 


\section{Introduction}

Polymeric resins are extensively used as matrices for structural composite materials due to their high stiffness, low creep, superior chemical resistance and excellent adhesion to fillers and fibers (Mallick 2007). The CTE of polymers is one of most important thermo-mechanical properties for designing polymer based composite structures when exposed to thermal environments. For instance, one of reasons for micro-crack phenomenon in fiber-reinforced polymers laminated composites during the temperature cycling is the difference of thermal properties like CTE between reinforcing fibers and resin. This matter becomes a serious problem for carbon fiberreinforced epoxy polymer (CFREP) laminated composites because the CTEs of carbon fibers is about $-12 \times 10^{-6}{ }^{\circ} C^{-1}$ while $65 \times 10^{-6}{ }^{\circ} C^{-1}$ for epoxy resins, respectively. Thus, it is preferred having epoxy resins with low CTE when carbon fibers as reinforcing phase. The other importance of polymer's CTE becomes evident when thermal stresses in composite structures are concentrated. Generally, when a composite structure is heated, it usually tends to expand and experiences thermal stress. It can be shown that the thermal expansion and thermal stress are extremely dependent on the CTE (Reddy 2004). That is why, resins with low CTE are desired for composite structures when they are used under thermal environments. Another importance of CTE of resins is related to the thermal buckling in composite elements. This destructive phenomenon happens in thin composites when the structures with special boundary constraints and lamination scheme are exposed to thermal environments. Thermal buckling of composite structures is known as a failure mode and should be prevented in practice. To this end, many researchers have studied the effective parameters on thermal buckling of composite structures like stacking sequence of layers, geometrical parameters and boundary conditions. Using resins with low CTE can also help to decrease the compressive thermal stresses and delay the critical buckling temperature. 
During last two decades, it has been shown that incorporation of nanomaterials such as CNTs can effectively improve thermo-mechanical properties of polymeric resin systems (Amir, BabaAkbarZarei and Khorasani 2019, Ayatollahi and Barbaz Isfahani 2017, Garg, Nam et al. 2019, Rafiee 2013, Rodríguez-González and Rubio-Gonzále 2019, Şansveren and Yaman 2019, Schadler, Giannaris, and Ajayan 1998, Sharma, and Mehta 2015, Siddiqui et al. 2009, Yazdi, 2019). However, many researchers have shown that, increasing weight percent of CNTs does not necessarily increase the mechanical properties of composites in a monotonically increasing manner. The challenge in incorporating CNTs into polymers arises from several perspectives. Because of CNT's high aspect ratio, CNTs are capable of entanglements and as a consequence they will be expected to give very high increases in the system viscosity as the individual nanotubes un-bundle, one from the other. A second consideration is that the individual tubes are difficult to separate from each other as a result of Van der Waals forces that tend to make them clump together (Rahmandoust and Ayatollahi 2016). Also, when CNTs can be dispersed effectively, only at relatively low loading levels of 0.1 to $0.5 \mathrm{wt} \%$ significant increase in mechanical properties of polymer matrices has been reported and by increasing the weight percent of loaded CNT, the properties decreased. The same trend was reported by previous studies as well (Maghsoudlou et al. 2019, Monfared, Ayatollahi and Isfahani 2018, Pötschke et al. 2003, Ren et al. 2003). Zhu et al. (2004) showed that increasing wt.\% of CNTs does not always enhance all mechanical properties of composites. Manchado et al. (2005) concluded that increasing volume fraction of CNTs does not increase composite mechanical properties in a monotonically increasing manner. Barai and Weng (2011) experimentally and numerically showed that CNT agglomeration and imperfect interface condition can seriously reduce the effective stiffness and elasto-plastic strength. Rahman et al. (2012 b) investigated the influence of amino functionalized MWCNTs on thermo- 
mechanical properties of e-glass/epoxy composites. They concluded that MWCNTs incorporation at low concentration ( $0.3 \mathrm{wt} \%$ as optimum loading $)$ improves thermal and mechanical properties of e-glass/epoxy laminated composites. They also showed that using only $0.3 \mathrm{wt} . \%$ loading of MWCNTs increases the strength, Young's modulus and strain to failure of e-glass/epoxy composite up to $37 \%, 21 \%$ and $21 \%$, respectively. It was also concluded from dynamic mechanical thermal analysis that the storage modulus, loss modulus and glass transition temperature $\left(T_{g}\right)$ of eglass/epoxy composites increase $41 \%, 52 \%$ and $10{ }^{\circ} \mathrm{C}$, respectively when $0.3 \mathrm{wt} \% \mathrm{CNT}$ was added to the epoxy resin. Anas et al. (2014) experimentally examined the effects of MWCNTs - as secondary reinforcements - on tensile strength, fiber-matrix bonding and interaction with the coupling agent in glass fiber/epoxy composites. From the experiments, it was observed that by using only $0.3 \mathrm{wt} \% \mathrm{CNTs}$, the tensile strength of the epoxy resin increases about $27 \%$.

As can be found from the literature survey, although worthwhile researches have been dedicated to analyze the effect of MWCNTs on mechanical characteristics of epoxy polymers, to the best of the authors' knowledge, there are few research works on the influence of nanotubes on polymer's CTE (Ansari, Hassanzadeh-Aghdam and Darvizeh 2016, Dos Santos et al. 2008, Hameed et al. 2015, He et al. 2018, Kundalwal and Meguid 2015, Rahman et al. 2012, Salam et al 2013, Sharma and Sharma 2016, Shirasu et al. 2017, Shirasu et al. 2015). Among those available, Santos et al. (2008) experimentally investigated the CTE of MWCNT/Epoxy composites. They considered only two types of nanocomposites with $0.1 \mathrm{wt} \%$ and $0.5 \mathrm{wt} \%$ CNTs and compared the result with the neat epoxy. The experiments revealed that the nanocomposite with less CNTs $(0.1 \mathrm{wt} \%)$ reduce the CTE of epoxy before and after $T_{g}$. On the other hand, it was found that, although nanocomposite with more CNTs does not have any effect on the CTE of epoxy when temperature is less than $T_{g}$, 
it increases the CTE after $T_{g}$. Rahman et al. (2012 a) investigated the effects of incorporating a uniformly dispersed $0.3 \mathrm{wt} . \%$ loading of MWCNTs into the pristine and polyol-toughened epoxy. They found that adding $0.3 \mathrm{wt} . \%$ MWCNTs could increase the stiffness of the composite and reduce CTE values of epoxy-based resins. Recently, He et al. (2018) used MWCNTs functionalized with $\mathrm{Fe}_{3} \mathrm{O}_{4}$ to improve thermo-mechanical properties of epoxy polymers. Their experimental results indicated that $\mathrm{Fe}_{3} \mathrm{O}_{4} / \mathrm{O}-\mathrm{MWCNTs}$ can increase the tensile strength, impact strength of epoxy resin and micro-cracks resistance at cryogenic temperature of carbon fiber reinforced epoxy polymer (CFREP) composites and decrease the CTEs of the epoxy resin.

Investigation of thermo-mechanical behavior of composite structures like beams, plates and shells reinforced with CNTs has gained considerable attention in the recent years. Many research works have been devoted to thermal behavior analysis of CNT-based composite structures (Ansari, Torabi and Shojaei 2017, Arefi and Soltan Arani 2018, Farzam and Hassani 2018, Kiani 2017, Sankar 2017, Shen 2012, Torabi, Ansari and Hassani 2019, Tung 2017). They mostly implemented micro-mechanical models to predict thermo-mechanical properties of CNT/polymer composites. However, these models always estimate composite material properties with an increasing trend versus CNTs. As it has been observed experimentally and stated above, increasing wt.\% of CNTs does not always enhance thermo-mechanical properties of the composites monotonically and further studies need to be conducted to clarify the matter.

The prime objective of the present work is exploring the effects of MWCNTs loading on thermal properties of nanocomposites in a board range of wt.\%. Nanocomposites with LY-5052 epoxy matrix and different wt.\% loading of MWCNTs $(0,0.1,0.3,0.5,0.7,1)$ are fabricated. The dispersion of the MWCNTs in the epoxy resin is made by ultrasound and high-speed shearing techniques. A detailed experimental analysis of influence of loading of MWCNTs into the epoxy 
resin on the CTE is carried out. Then, as for the second purpose, this research work aims at thermal stability analysis of rectangular CNTCF laminated plates. The main purpose is to investigate the influence of CNTs on thermal buckling of rectangular CFREP laminated composite plates. To this end, using the experimental data and micro-mechanical models, the thermo-elastic properties of hybrid CFRCNTEP composite plates are predicted. After the estimation of thermo-elastic features, based on the FSDT and using GDQ approach which has been successfully applied for analysis of composite structures (Golchi, Talebitooti and Talebitooti 2019, Shahedi and Mohammadimehr 2019, Zarezadeh, Hosseini and Hadi 2019), the effect of adding CNTs into the epoxy resin on critical buckling temperature of structure with respect to the geometrical parameters, stacking sequence of layers and boundary conditions are comprehensively studied. Due to the absence of similar results in the specialized literature, this paper is likely to fill a gap in the-state-of the-art of MWCNT/epoxy and CFRCNTEP composites.

\section{Materials and Structures}

\subsection{Materials}

Epoxy-based resins are widely used as matrix for composite materials. In this research work, the low-viscosity commercially available Araldite LY-5052 epoxy and Aradur HY-5052 hardener both purchased from Huntsman Corporation were used. This low viscosity epoxy makes the dispersion of additives and fabrication of composite specimens easier at the room temperature. MWCNTs used in this work were produced by the US Research nanomaterials. They are characterized by purity $>95 \%$, outer diameter: $20-30 \mathrm{~nm}$, inner diameter: $5-10 \mathrm{~nm}$, tube length range: 10-30 um, specific surface area $>110 \mathrm{~m}^{2} / \mathrm{gr}$, and density: $2100 \mathrm{Kg} / \mathrm{m}^{3}$. 


\subsection{Sample preparation}

The polymer-matrix nanocomposites were prepared by ultrasound method as the simplest and most convenient high-power dispersion approach. Five types of nanocomposites containing 0, 0.1, 0.3, 0.5, 0.7 and $1 \mathrm{wt} . \%$ of MWCNTs were prepared separately as shown in Fig. 1 and described below:

First, the desired amounts of MWCNTs were weighed and mixed with the required amount of epoxy and stirred for $10 \mathrm{~min}$ at $500 \mathrm{rpm}$ (Steps 1-2). The mixtures containing $0.1,0.3,0.5,0.7$ or 1 wt.\% of MWCNTs were then sonicated for 50-70 min by a conventional ultrasonic (Step 3). During the sonication, the mixture container was held in iced water to keep the temperature around room temperature. In order to make sure the sonication energy was transferred uniformly to the whole mixture, the mixture was stirred every $5 \min$ by a small spoon. Finally, to remove any bubble, the produced mixture was degassed in vacuum oven at room temperature for 15 min (Step 4). Six types of polymeric specimens (pure and nanocomposites) were initially fabricated by casting into the molds (considering sample dimensions characterized by the ASTM E831 standard) and curing for $24 h$ at room temperature, $25{ }^{\circ} C$ (Step 5). The samples were then removed from the molds and post-cured for $1 \mathrm{~h}$ at $100{ }^{\circ} \mathrm{C}$. Finally, the different types of samples were prepared to be investigated by TMA (Step 6).

\subsection{Thermo-mechanical properties of nanocomposites polymer}


Here, the approach by which thermo-mechanical properties epoxy/polymer matrix were calculated is described.

\section{CTE of polymer matrix:}

To obtain the CTE of the polymer matrix (pure epoxy and CNT/epoxy), thermo-mechanical analysis (TMA) was performed using TMA 500 device. In order to examine the accuracy of the analysis, first, the mean value of CTE was measured for pure epoxy ranging $20-100^{\circ} \mathrm{C}$. Based on the obtained data from the experiment, the CTE for the pure polymer was found to be $66 \times 10^{-6} /{ }^{\circ} \mathrm{C}$. It was compared with data sheet from the manufacturer listed in Table 1 . A good agreement was observed between the results verifying accuracy of the fabrication procedure. Thus, the data of TMA test are accurate and acceptable for this research work.

In the next step, the CTE for nanocomposite polymer matrix containing $0,0.1,0.3,0.5,0.7$ and 1 wt.\% of MWCNTs was measured and represented in Fig. 2 and Table 2. The preliminary conclusion drawn from this figure is the fact that CTE has a decreasing-increasing trend against adding MWCNTs. In fact, the dependency of thermal properties of polymer matrix on wt.\% of MWCNTs is not monotonic. As it can be seen, increasing wt. $\%$ of MWCNTs up to 0.3 reduces the CTE, while further increase has a negative effect and enhances the CTE. This phenomenon can be related to MWCNT agglomeration that dramatically influences CTE. To investigate the state of MWCNTs dispersion, three samples of the nanocomposite specimens with $0.3,0.5$ and $1 \mathrm{wt} . \%$ of MWCNTs are comparatively studied using transmission electron microscopy (TEM) as shown in Fig. 3. This figure illustrates the state of dispersion of fillers with different loadings. According to Fig. 3- $a$, a good dispersion of MWCNTs is observed for the specimen containing $0.3 \mathrm{wt}$. \% of MWCNTs while some local MWCNT agglomerations are observed for the specimens with 0.5 
and 1 wt. $\%$ of MWCNTs as shown in Figs. $3 \mathrm{~b}$ and c. Therefore, it can be concluded that the optimum amount of nanotubes in order to decrease the CTE of polymers is $0.3 \mathrm{wt} \%$. Similar results have also been reported by other researchers for mechanical properties of nanocomposite polymers that proves the fact that at an optimum amount of $\mathrm{wt} \%$ of CNTs, some material properties like Young's modulus sharply changes (Manchado et al. 2005).

The results presented in Fig. 2 reveal that nanocomposite with 0.3 wt.\% of MWCNTs has minimum CTE of $44 \times 10^{-6} /{ }^{\circ} \mathrm{C}$ that is $33 \%$ smaller than its value for the pure polymer. Since the main scope of the present work is related to the thermal buckling behavior of nanocomposite structures, 0.3 wt.\% of MWCNTs is considered as optimum amount of nanotubes. Fig. 2 also illustrates that the CTE of CNT reinforced polymer cannot be calculated using rule-of-mixture applied in many previous researches. According to this rule, the CTE of nanocomposite is always decreased by increasing wt.\% of MWCNTs. However, this is in contrast with experimental observations in the present research work. It should be mentioned that the rule of mixture is not also valid for composites with short fibers. Furthermore, it is not able to consider the agglomeration effect of CNTs.

\section{Mechanical properties of epoxy/polymer matrix:}

The dependency of Young's modulus of the polymer-based composites on the low wt.\% of MWCNTs can be estimated by various micro-mechanical methods. Qian et al. (2000) showed that if reinforcing MWCNTs bond strongly to the matrix, the external load is transmitted from the matrix to MWCNTs via the interfacial shear stress. Considering MWCNTs as randomly oriented discontinuous fiber lamina, Young's modulus of the nanocomposite, $E_{N C}$, can be calculated as (Qian et al. 2000): 


$$
\begin{aligned}
& E_{N C}=\left[\frac{3}{8} \frac{1+2\left(l_{N T} / d_{N T}\right) \eta_{L} V_{N T}}{1-\eta_{L} V_{N T}}+\frac{5}{8} \frac{1+2 \eta_{T} V_{N T}}{1-\eta_{T} V_{N T}}\right] E_{P} \\
& \eta_{L}=\frac{\left(E_{N T} / E_{P}\right)-1}{\left(E_{N T} / E_{P}\right)+2\left(l_{N T} / d_{N T}\right)} \\
& \eta_{T}=\frac{\left(E_{N T} / E_{P}\right)-1}{\left(E_{N T} / E_{P}\right)+2}
\end{aligned}
$$

where $E_{P}$ and $E_{N T}$ are Young's modulus of the polymer matrix and MWCNTs, respectively. $l_{N T}$ and $d_{N T}$ are the length and the outer diameter of the MWCNT, while $V_{N T}$ denotes its volume fraction. Qian et al. (2000) used the above equation to calculate Young's modulus of polystyrene matrix reinforced by MWCNTs. They compared the experimental data with those obtained by the theoretical model of Eq. (1) and concluded that the mentioned model can predict the Young modulus of nanocomposite matrix with enough accuracy. Therefore, in this step, Eq. (1) is applied as an acceptable model to obtain the Young Modulus of MWCNT-reinforced polymer matrix. Using this solution, no experiment is needed to calculate the Young's modulus of nanocomposite polymer. Here, Young's modulus of the polymer is $3.1 \mathrm{GPa}$ as reported by the manufacturer. Average values are considered for outer diameter and length of the MWCNT. Its Young's modulus is given by $0.2-0.8 \mathrm{TPa}$. Average Young's modulus is calculated by Eq. (1) for $0.3 \mathrm{wt} \%$ of MWCNTs as $3.38 \mathrm{GPa}$ that is $9 \%$ higher than pure polymeric one.

According to the data sheet from the manufacturer, the Poisson's ratio of the pure polymer is 0.35 . Spanosa and Kontsos. (2008) showed that CNTs don't affect the Poisson's ratio of polymers by a considerable amount. Besides, for nanocomposite matrix and long carbon fibers, it is possible to use rule of mixture to calculate the Poisson's ratio of whole system. Thus, though the volume fraction of long carbon fibers in the present study is assumed to be $60 \%$, the Poisson's ratio of hybrid composite system (CNT/Polymer/Carbon fibers) cannot change sharply. Therefore, the 
Poisson's ratio of nanocomposite matrix with 0.3 wt.\% of MWCNTs can be assumed to be 0.35 . A summary of the thermo-mechanical properties of pure polymer and nanocomposite with 0.3 wt.\% of MWCNTs adopted from different methods is presented in Table 3.

\subsection{Thermo-mechanical properties of CFREP and CFRCNTEP composites}

In the present work, long carbon fibers are assumed to reinforce pure epoxy and nanocomposites. Thermo-mechanical properties of carbon fibers are listed in Table 4 where $E_{1}, E_{2}, G_{12}, v_{12}, \alpha_{1}, \alpha_{2}$ denote longitudinal and transverse Young's moduli, in-plane shear modulus, major Poisson's ratio, longitudinal and transverse thermal expansion coefficients, respectively. Having thermomechanical properties of pure epoxy, nanocomposite matrix and carbon fibers, material properties of CFREP and CFRCNTEP composites can be calculated from rule of mixture. The elastic properties of the long fiber-reinforced polymer composite are expressed as:

$$
\begin{aligned}
& \text { Young's modulus: } \\
& E_{1}=E_{1}^{f} V^{f}+E^{m} V^{m} \\
& \frac{1}{E_{2}}=\frac{\eta^{f} V^{f}}{E_{2}^{f}}+\frac{\eta^{m} V^{m}}{E^{m}} \\
& \eta^{f}=\frac{E_{1}^{f} V^{f}+\left[\left(1-v_{12}^{f} v_{21}^{f}\right) E^{m}+v^{m} v_{21}^{f} E_{1}^{f}\right] V^{m}}{E_{1}^{f} V^{f}+E^{m} V^{m}} \\
& \eta^{m}=\frac{E^{m} V^{m}+\left[\left(1-\left(v^{m}\right)^{2}\right) E_{1}^{f}-\left(1-v^{m} v_{12}^{f}\right) E^{m}\right] V^{f}}{E_{1}^{f} V^{f}+E^{m} V^{m}}
\end{aligned}
$$


Thermal expansion coefficient:

$$
\begin{aligned}
& \alpha_{1}=\frac{\alpha_{1}^{f} E_{1}^{f} V^{f}+\alpha^{m} E^{m} V^{m}}{E_{1}^{f} V^{f}+E^{m} V^{m}} \\
& \alpha_{2}=\alpha_{2}^{f} V^{f}+\alpha^{m} V^{m}+\left(\frac{E_{1}^{f} v^{m}+E^{m} v_{12}^{f}}{E_{1}}\right)\left(\alpha^{m}-\alpha_{1}^{f}\right)\left(1-V^{f}\right) V^{f}
\end{aligned}
$$

Poisson's ratio: $\quad v_{12}=v_{12}^{f} V^{f}+v^{m} V^{m}$

where subscripts 1 and 2 are related to the materials properties along the fiber direction and perpendicular to the fiber direction. Also, the superscripts ' $m$ ' and ' $f$ ' mean the matrix and carbon fiber, respectively. Considering material properties of pure epoxy, nanocomposite with 0.3 wt.\% of MWCNTs and carbon fibers, the elastic properties of CFREP and CFRCNTEP composites with $V^{f}=0.6$ are calculated and presented in Table 5. Comparing material properties of CFREP and CFRCNTEP composite reveals that, MWCNTs result in minor and major improvements in mechanical and thermal properties of the composite. As it can be seen, adding up 0.3 wt. $\%$ of MWCNTs to the CFREP composite improves the CTE by $156.19 \%$ and $26.57 \%$ along the fiber direction and perpendicular to the fiber direction, respectively.

\subsection{Governing equations}

Consider a rectangular carbon-fiber/MWCNT/epoxy laminated composite plate as displayed in Fig. 4. The plate length is $a$ and its width and total thickness are denoted by $b$ and $h$, respectively. Orthogonal coordinate system namely $(x, y, z)$ as shown in Fig. 4 is located on the middle surface of the composite plate. 
Based on the FSDT, the governing equations for thermal buckling of symmetrically laminated plate are derived as (Reddy 2004):

$$
\begin{aligned}
& D_{11}\left(\frac{\partial^{2} \phi_{x}}{\partial x^{2}}\right)+D_{12}\left(\frac{\partial^{2} \phi_{y}}{\partial x \partial y}\right)+D_{66}\left(\frac{\partial^{2} \phi_{x}}{\partial y^{2}}+\frac{\partial^{2} \phi_{y}}{\partial x \partial y}\right)-k_{s} A_{55}\left(\phi_{x}+\frac{\partial w}{\partial x}\right)-k_{s} A_{45}\left(\phi_{y}+\frac{\partial w}{\partial y}\right) \\
& +2 D_{16} \frac{\partial^{2} \phi_{x}}{\partial x \partial y}+D_{16} \frac{\partial^{2} \phi_{y}}{\partial x^{2}}+D_{26} \frac{\partial^{2} \phi_{y}}{\partial y^{2}}=0 \\
& D_{66}\left(\frac{\partial^{2} \phi_{y}}{\partial x^{2}}+\frac{\partial^{2} \phi_{x}}{\partial x \partial y}\right)+D_{12}\left(\frac{\partial^{2} \phi_{x}}{\partial x \partial y}\right)+D_{22}\left(\frac{\partial^{2} \phi_{y}}{\partial y^{2}}\right)-k_{s} A_{44}\left(\phi_{y}+\frac{\partial w}{\partial y}\right)-k_{s} A_{45}\left(\phi_{x}+\frac{\partial w}{\partial x}\right) \\
& +D_{16} \frac{\partial^{2} \phi_{x}}{\partial x^{2}}+D_{26} \frac{\partial^{2} \phi_{x}}{\partial y^{2}}+2 D_{26} \frac{\partial^{2} \phi_{y}}{\partial x \partial y}=0 \\
& k_{s} A_{55}\left(\frac{\partial \phi_{x}}{\partial x}+\frac{\partial^{2} w}{\partial x^{2}}\right)+k_{s} A_{44}\left(\frac{\partial \phi_{y}}{\partial y}+\frac{\partial^{2} w}{\partial y^{2}}\right)+k_{s} A_{45}\left(\frac{\partial \phi_{x}}{\partial y}+\frac{\partial \phi_{y}}{\partial x}+2 \frac{\partial^{2} w}{\partial x \partial y}\right) \\
& -N_{x}^{T} \frac{\partial^{2} w}{\partial x^{2}}-2 N_{x y}^{T} \frac{\partial^{2} w}{\partial x \partial y}-N_{y}^{T} \frac{\partial^{2} w}{\partial y^{2}}-=0
\end{aligned}
$$

in which $w, \phi_{x}$ and $\varphi_{y}$ denote transvers deflection of the middle surface, and the rotations of the middle surface of the plate about $y$ and $x$ axes, respectively. In addition, $k_{s}$ represents the shear correction factor, $A_{i j}$ and $D_{i j}$ are the transformed stretching stiffness and bending stiffness coefficient, respectively, and $N_{x}^{T}, N_{y}^{T}$ and $N_{x y}^{T}$ are thermal force resultants (Reddy 2004). In the present work, simply supported and clamped boundary conditions are considered for the structure. For simplicity and convenience, the letters $S$ and $C$ are utilized to signify a simply supported edge and a clamped edge, respectively. For instance, $S C S C$ denotes a plate which is simply supported at $x=0, a$ and is clamped at $y=0, b$. Boundary conditions for SSSS, SCSC and CCCC plates are considered as: 
SSSS :

$W=0 ; \varphi_{y}=0 ; D_{11} \frac{\partial \varphi_{x}}{\partial x}+D_{12} \frac{\partial \varphi_{y}}{\partial y}+D_{16}\left(\frac{\partial \varphi_{x}}{\partial y}+\frac{\partial \varphi_{y}}{\partial x}\right)=0$, at $x=0, a$

$W=0 ; \varphi_{x}=0 ; \quad D_{12} \frac{\partial \varphi_{x}}{\partial x}+D_{22} \frac{\partial \varphi_{y}}{\partial y}+D_{26}\left(\frac{\partial \varphi_{x}}{\partial y}+\frac{\partial \varphi_{y}}{\partial x}\right)=0 \quad$, at $y=0, b$

SCSC :

$W=0 ; \varphi_{y}=0 ; D_{11} \frac{\partial \varphi_{x}}{\partial x}+D_{12} \frac{\partial \varphi_{y}}{\partial y}+D_{16}\left(\frac{\partial \varphi_{x}}{\partial y}+\frac{\partial \varphi_{y}}{\partial x}\right)=0$, at $x=0, a$

$W=0 ; \varphi_{x}=0 ; \varphi_{y}=0$, at $y=0, b$

\section{CCCC :}

$W=0 ; \varphi_{x}=0 ; \varphi_{y}=0$, at $x=0, a ; y=0, b$

Here, GDQ method as a powerful technique is employed to solve the governing equations (6)-(8) and obtain the buckling temperature of the structure. Based on the purposed method, the $n$th order of a continuous function $f(\zeta)$ with respect to $\zeta$ at a given point $\zeta_{i}$ can be approximated as a linear sum of weighting values at all of the discrete point in the domain of $\zeta$ (Bellman and Casti 1971, Shu and Richards, 1992),

$$
\frac{\partial f^{n\left(\zeta_{i}\right)}}{\partial \zeta^{n}}=\sum_{j=1}^{N_{\zeta}} c_{i j}^{n} f\left(\zeta_{j}\right),\left(i=1,2, N_{\zeta}, n=1,2, \ldots, N_{\zeta}-1\right)
$$

where $N_{\zeta}$ is the number of sampling points, and $c_{i j}^{n}$ is the $\zeta_{j}$ dependent weight coefficient.

\section{Thermal buckling study}

In this section, first, convergence and comparison studies are conducted to check the accuracy of the present solution. Afterward, parametric studies are performed to investigate the influences of geometric and material parameters on the thermal buckling behaviour of carbon-fibre-reinforced nanocomposite rectangular plates. 


\subsection{Convergence and comparison study}

In order to validate the present formulation and solution methodology, critical buckling temperatures of rectangular CFREP laminated plates are predicted and compared with those reported in the literature. The present GDQ method with $7 \times 7,9 \times 9,13 \times 13$ and $17 \times 17$ grid points is implanted to compute critical buckling temperature parameter $\left(\lambda_{T}=\alpha_{0} \Delta T_{c r}\right)$ of $\left[0^{\natural} / 90^{\natural}\right]_{S}$ CFREP plates with SSSS and CCCC boundary conditions. The geometrical dimensions are $a / b=1$ and $h / b=0.01$, and the material properties are as follows (Kant and Babu 2000):

$$
\begin{aligned}
& \frac{E_{1}}{E_{2}}=15, E_{2}=E_{3}, \frac{G_{12}}{E_{2}}=\frac{G_{13}}{E_{2}}=0.5, \frac{G_{23}}{E_{2}}=0.3356, v_{12}=v_{13}=0.3, \\
& \frac{\alpha_{1}}{\alpha_{0}}=0.015, \frac{\alpha_{2}}{\alpha_{0}}=\frac{\alpha_{3}}{\alpha_{0}}=1, \alpha_{0}=10^{-6} 1 /^{0} \mathrm{C}
\end{aligned}
$$

The results are presented in Table 6 and compared with their counterparts reported by Kant and Babu (2000). As it is evident, the results are so close to each other. Hence, it is concluded that GDQ can predict buckling temperatures of composite structures with high accuracy.

\subsection{Parametric studies}

In this section, thermal buckling behaviours of carbon-fibre-reinforced MWCNT/epoxy-based composite laminated rectangular plates are investigated. As experimentally observed in Fig. 2, the nanocomposite with $0.3 \mathrm{wt} . \%$ of MWCNTs has the minimum CTE of $44 \times 10^{-6}{ }^{\mathrm{n}} \mathrm{C}^{-1}$ and therefore is considered as nanocomposite matrix in this section. The influence of MWCNTs on the thermal buckling of the composite rectangular plate with lamination scheme of $\left[30^{\square} /-45^{\square} / 90^{\square}\right]_{s}$ and length-to-width ratio of unity $(a / b=1)$ is examined in Table 7. Critical buckling temperature difference is presented for composite plates with pure epoxy and MWCNT/epoxy matrices and 
different thickness-to-length ratio, $h / b$. As expected, with the increase of thickness of plate the critical buckling temperature severely increases. Inspecting data given in Table 7 and Fig. 5, one can conclude that adding MWCNTs always enhances thermal buckling stability of the structure with various thicknesses. It has the same effect on the thermal buckling behaviour of plate with different thickness plates. It is observed that the critical buckling temperature of structure is improved around $37-39 \%$ for all plates.

In Table 8, the role of MWCNTs in variations of thermal buckling characteristics of a $\left[30^{\natural} /-45^{\square} / 90^{\natural}\right]_{s}$ laminated plate with geometric parameters of $a / b=1, h / b=0.01$ for different types of boundary conditions is examined. It is obvious that the minimum, moderate and maximum values of $\Delta T_{c r}$ correspond to SSSS, SCSC and CCCC cases, respectively. In fact, more constraints at the end edges enhance the structural stiffness resulting in a higher critical buckling temperature. It is also found that adding CNT into polymer matrix increases the critical buckling temperature of structure and this improvement is almost the same (37-39\%) for various types of boundary conditions.

Here, the influence of CNTs on the buckling temperature of laminated composite plates is investigated with respect to the carbon fiber angle. To this end, a square plate with angle-ply lamination scheme of $[\theta /-\theta]_{s}$ is considered. The critical buckling temperature of the plate is calculated for various fiber angle $\theta$ which can vary between $-90^{\circ}$ and $90^{\circ}$, and the results are depicted in Fig. 6. This figure reveals that CNTs always have a positive effect on the thermal buckling stability of the plate with different lamination schemes $\left(-90^{\circ} \leq \theta \leq 90^{\circ}\right)$ and can enhance the critical buckling temperature of considered plate between $35 \%$ to $38.5 \%$. 
In previous figures and tables, only the square type of plates was considered. The numerical results clarified that the CNTs are able to improve the buckling temperature of square laminated plates from 35 up to $38.5 \%$ for different $h / b$ ratios, various lamination scheme and all types of boundary conditions. Now, the role of CNTs in variations of thermal buckling behavior of rectangular plates is examined. For this purpose, a diagram is presented to show the variations of buckling temperature against length-to-width parameter. Fig. 7 illustrate that CNTs always play a positive role in thermal buckling of composite plates with different $a / b$ ratios. From Fig. 8, it is also concluded that with increase of $a / b$ ratio, the CNTs become more effective at improving the stability of structure. In other words, the long plates are more affected by CNTs in comparison with square ones. The numerical results of Fig. 8 show that the thermal buckling characteristic of rectangular plates can be improved up to $42 \%$.

\section{Conclusion}

The present research was dedicated to analyse and predict thermal properties of MWCNT/epoxy composites as well as thermal stability of carbon-fiber-reinforced MWCNT/epoxy composite laminated plates. Nanocomposites with epoxy matrix and different wt.\% of MWCNTs $(0,0.1,0.3$, $0.5,0.7,1)$ were made by ultrasound and high-speed shearing techniques. Thermal expansion coefficient of MWCNT/epoxy composites were measured and the effects of incorporating MWCNTs in the epoxy matrix were studied. Experimental results revealed that the CTE has a decreasing-increasing trend against adding up MWCNTs and becomes minimum for $0.3 \mathrm{wt} \%$ of MWCNTs. Rule of mixture model were then implemented to calculate thermo-mechanical properties of carbon-fiber-reinforced MWCNT/epoxy composites. Then, thermal stability of 
rectangular laminated composite plates made of carbon-fiber-reinforced MWCNT/epoxy composite laminae with low thermal expansion was investigated numerically. Based on FSDT and by using GDQ approach, a parametric study was performed to demonstrate the effects of MWCNT on thermal buckling of laminated rectangular plates. It was found that MWCNT is a highly promising reinforcement for carbon-fiber-reinforced composite structures in thermal environments. Results clarified that adding 0.3 wt.\% of MWCNTs can improve critical buckling temperature around $35-42 \%$ for different thicknesses-to-width and length-to-width ratios, various stacking sequences of layers and all types of boundary conditions. The benchmark results provided in this work are expected to contribute to a better understanding on thermo-mechanical behaviours of MWCNT/epoxy-based composites and would be beneficial toward optimal design of these composite structures. 


\section{References}

Amir, S., H. BabaAkbar-Zarei and M. Khorasani. 2019. Flexoelectric vibration analysis of nanocomposite sandwich plates. Mechanics Based Design of Structures and Machines 1-18. doi: 10.1080/15397734.2019.1624175.

Anas, S., G.U. Rehman, Z.M. Khan, N. Ul-Haq, M.B. Khan, S. Nauman, M. Shahid and A Nasir. 2014. Influence of MWCNTs as secondary reinforcement material in glass fiber/epoxy composites fabricated using VARTM. Applied Polymer Composites 2(1): 17-26.

Ansari, R., M. K. Hassanzadeh-Aghdam and A. Darvizeh. 2016. Coefficients of thermal expansion of carbon nanotube-reinforced polyimide nanocomposites: A micromechanical analysis. Proceedings of the Institution of Mechanical Engineers, Part L: Journal of Materials: Design and Applications, p.1464420716666106. doi:10.1177/1464420716666106.

Ansari, R., J. Torabi, and M. Faghih Shojaei. Buckling and vibration analysis of embedded functionally graded carbon nanotube-reinforced composite annular sector plates under thermal loading. Composites Part B: Engineering 109: 197-213. doi: 10.1016/j.compositesb.2016.10.050.

Arefi, M. and A. H. Soltan Arani. 2018. Higher order shear deformation bending results of a magneto-electro-thermoelastic functionally graded nanobeam in thermal, mechanical, electrical, and magnetic environments. Mechanics Based Design of Structures and Machines, 46(6): 669-692. doi: 10.1080/15397734.2018.1434002.

Ayatollahi, M.R., R. Barbaz Isfahani and R. Moghimi Monfared. 2017. Effects of multi-walled carbon nanotube and nanosilica on tensile properties of woven carbon fabric-reinforced epoxy composites fabricated using VARIM. Journal of Composite Materials, 51(30): 4177-4188. doi: $10.1177 / 0021998317699982$.

Barai, P. and G.J. Weng. 2011. A theory of plasticity for carbon nanotube reinforced composites. International Journal of Plasticity, 27(4): 539-559. doi: 10.1016/j.ijplas.2010.08.006.

Bellman, R. and J. Casti. 1971. Differential quadrature and long-term integration. Journal of Mathematical Analysis and Applications 34(2): 235-238. doi: 10.1016/0022-247X(71)901107.

Dos Santos, A.S., T.D.O. Leite, C.A. Furtado, C. Welter, L. C. Pardini and G.G. Welter. 2008. Morphology, thermal expansion, and electrical conductivity of multiwalled carbon nanotube/epoxy composites. Journal of applied polymer science 108(2): 979-986. doi: 10.1002/app.27614.

Farzam, A. and B. Hassani. 2018. Thermal and mechanical buckling analysis of FG carbon nanotube reinforced composite plates using modified couple stress theory and isogeometric approach. Composite Structures 206:774-790. doi: 10.1016/j.compstruct.2018.08.030.

Garg, M., S. Sharma and R. Mehta. 2015. Pristine and amino functionalized carbon nanotubes reinforced glass fiber epoxy composites. Composites Part A: Applied Science and Manufacturing 76: 92-101. doi: 10.1016/j.compositesa. 2015.05.012.

Golchi, M., M. Talebitooti and R. Talebitooti. 2019. Thermal buckling and free vibration of FG truncated conical shells with stringer and ring stiffeners using differential quadrature method. Mechanics Based Design of Structures and Machines 47(3): 255-282. doi: 10.1080/15397734.2018.1545588.

Hameed, A., M. Islam, I. Ahmad, N. Mahmood, S. Saeed and H. Javed. 2015. Thermal and mechanical properties of carbon nanotube/epoxy nanocomposites reinforced with pristine and 

$10.1002 /$ pc. 23097.

He, Y., S. Yang, H. Liu, Q. Shao, Q. Chen, C. Lu, Y. Jiang, C. Liu and Z. Guo. 2018. Reinforced carbon fiber laminates with oriented carbon nanotube epoxy nanocomposites: Magnetic field assisted alignment and cryogenic temperature mechanical properties. Journal of colloid and interface science 517: 40-51. doi: 10.1016/j.jcis.2018.01.087.

Kant, T.A.R.U.N. and C.S. Babu. 2000. Thermal buckling analysis of skew fiber-reinforced composite and sandwich plates using shear deformable finite element models. Composite Structures 49(1): 77-85. doi: 10.1016/S0263-8223(99)00127-0.

Kiani, Y., 2017. Thermal buckling of temperature-dependent FG-CNT-reinforced composite skew plates. Journal of Thermal Stresses 40(11): 1442-1460. doi: 10.1080/01495739.2017.1336742.

Kundalwal, S.I. and S.A. Meguid. 2015. Micromechanics modelling of the effective thermoelastic response of nano-tailored composites. European Journal of Mechanics-A/Solids 53: 241-253. doi: 10.1016/j.euromechsol.2015.05.008.

Maghsoudlou, M.A., R. B. Isfahani, S. Saber-Samandari and M. Sadighi. 2019. Effect of interphase, curvature and agglomeration of SWCNTs on mechanical properties of polymerbased nanocomposites: Experimental and numerical investigations. Composites Part B: Engineering 175: 107119. 10.1016/j.compositesb.2019.107119.

Mallick, P.K., 2007. Fiber-reinforced composites: materials, manufacturing, and design. CRC press.

Manchado, M.L., L. Valentini, J. Biagiotti and J.M. Kenny. 2005. Thermal and mechanical properties of single-walled carbon nanotubes-polypropylene composites prepared by melt processing. Carbon 43(7): 1499-1505. 10.1016/j.carbon.2005.01.031.

Monfared, R.M., M. R. Ayatollahi and R. B. Isfahani. 2018. Synergistic effects of hybrid MWCNT/nanosilica on the tensile and tribological properties of woven carbon fabric epoxy composites. Theoretical and Applied Fracture Mechanics 96: 272-284. doi: 10.1016/j.tafmec.2018.05.007.

Nam, T.H., K. Goto, Y. Shimamura, Y. Inoue and S. Ogihara. 2019. Property improvement of CNT spun yarns and their composites through pressing, stretching and tensioning. Advanced Composite Materials: 1-18. doi: 10.1080/09243046.2019.1610586.

Pötschke, P., A. R. Bhattacharyya, A. Janke and H. Goering. 2003. Melt mixing of polycarbonate/multi-wall carbon nanotube composites. Composite Interfaces, 10(4-5): 389404. doi: 10.1163/156855403771953650.

Qian, D., E.C. Dickey, R. Andrews and T. Rantell. 2000. Load transfer and deformation mechanisms in carbon nanotube-polystyrene composites. Applied physics letters 76(20): 28682870. doi: 10.1063/1.126500@ap1.2019.APLCLASS2019.issue-1.

Rafiee, R., 2013. Influence of carbon nanotube waviness on the stiffness reduction of CNT/ polymer composites. Composite Structures 97: 304-309. doi: 10.1016/j.compstruct.2012.10.028.

Rahman, M.M., M. Hosur, A.G. Ludwick, S. Zainuddin, A. Kumar, J. Trovillion and S. Jeelani. 2012 a. Thermo-mechanical behavior of epoxy composites modified with reactive polyol diluent and randomly-oriented amino-functionalized multi-walled carbon nanotubes. Polymer Testing 31(6): 777-784. doi: 10.1016/j.polymertesting.2012.05.006.

Rahman, M.M., S. Zainuddin, M. V. Hosur, J. E. Malone, M.B.A. Salam, A. Kumar and S. Jeelani. 2012 b. Improvements in mechanical and thermo-mechanical properties of e-glass/epoxy 
composites using amino functionalized MWCNTs. Composite Structures. 94(8): 2397-2406. doi: 10.1016/j.compstruct.2012.03.014.

Rahmandoust, M. and M. R. Ayatollahi. 2016. Characterization of carbon nanotube based composites under consideration of defects, Vol. 1, 12-17. Switzerland: Springer International Publishing.

Reddy, J.N., 2004. Mechanics of laminated composite plates and shells: theory and analysis. CRC press.

Ren, Y., F. Li, H. M. Cheng and K. Liao. 2003. Tension-tension fatigue behavior of unidirectional single-walled carbon nanotube reinforced epoxy composite. Carbon 41(11): 2177-2179. doi: 10.1016/S0008-6223(03)00248-3.

Rodríguez-González, J.A. and C. Rubio-González. 2019. Influence of sprayed multi-walled carbon nanotubes on mode I and mode II interlaminar fracture toughness of carbon fiber/ epoxy composites. Advanced Composite Materials, 28: 19-36. doi: 10.1080/09243046.2018.1458510.

Salam, M.B.A., M.V. Hosur, S. Zainuddin and S. Jeelani. 2013. Improvement in mechanical and thermo-mechanical properties of epoxy composite using two different functionalized multiwalled carbon nanotubes. Open Journal of Composite Materials 3(2A): 1-9. doi: 10.4236/ojcm.2013.32A001.

Sankar, A., S. Natarajan, T. Merzouki and M. Ganapathi. 2017. Nonlinear dynamic thermal buckling of sandwich spherical and conical shells with CNT reinforced facesheets. International Journal of Structural Stability and Dynamics, 17(09): 1750100. doi: 10.1142/S0219455417501000.

Şansveren, M.F. and M. Yaman. 2019. The Effect of Carbon Nanofiber on the Dynamic and Mechanical Properties of Epoxy/Glass Microballoon Syntactic Foam. Advanced Composite Materials 1-15. doi: 10.1080/09243046.2019.1610929.

Schadler, L.S., S.A. Giannaris, and P.M. Ajayan, 1998. Load transfer in carbon nanotube epoxy composites. Applied physics letters 73(26): 3842-3844.doi: 10.1063/1.122911.

Shahedi, S. and M. Mohammadimehr. 2019. Vibration analysis of rotating fully-bonded and delaminated sandwich beam with CNTRC face sheets and AL-foam flexible core in thermal and moisture environments. Mechanics Based Design of Structures and Machines 1-31. doi: 10.1080/15397734.2019.1646661.

Sharma, M. and V. Sharma. 2016. Chemical, mechanical, and thermal expansion properties of a carbon nanotube-reinforced aluminum nanocomposite. International Journal of Minerals, Metallurgy, and Materials, 23(2) 222-233. doi: 10.1007/s12613-016-1230-3.

Shen, H.S., 2012. Thermal buckling and postbuckling behavior of functionally graded carbon nanotube-reinforced composite cylindrical shells. Composites Part B: Engineering 43(3): 1030-1038. doi: 10.1016/j.compositesb.2011.10.004.

Shirasu, K., A. Nakamura, G. Yamamoto, T. Ogasawara, Y. Shimamura, Y. Inoue and T. Hashida. 2017. Potential use of CNTs for production of zero thermal expansion coefficient composite materials: An experimental evaluation of axial thermal expansion coefficient of CNTs using a combination of thermal expansion and uniaxial tensile tests. Composites Part A: Applied Science and Manufacturing 95: 152-160. doi: 10.1016/j.compositesa.2016.12.027.

Shirasu, K., G. Yamamoto, I. Tamaki, T. Ogasawara, Y. Shimamura, Y. Inoue and T. Hashida. 2015. Negative axial thermal expansion coefficient of carbon nanotubes: Experimental determination based on measurements of coefficient of thermal expansion for aligned carbon nanotube reinforced epoxy composites. Carbon 95: 904-909. doi: 10.1016/j.carbon.2015.09.026. 
Shu, C. and B. E. Richards 1992. Application of generalized differential quadrature to solve two-dimensional incompressible Navier-Stokes equations. International Journal for Numerical Methods in Fluids, 15(7): doi: 791-798. 10.1002/fld.1650150704.

Siddiqui, N.A., M.L. Sham, B.Z. Tang, A. Munir and J.K. Kim, 2009. Tensile strength of glass fibres with carbon nanotube-epoxy nanocomposite coating. Composites Part A: Applied Science and Manufacturing 40(10): 1606-1614. doi: 10.1016/j.compositesa.2009.07.005.

Spanos, P.D. and A. Kontsos. 2008. A multiscale Monte Carlo finite element method for determining mechanical properties of polymer nanocomposites. Probabilistic Engineering Mechanics 23(4): 456-470. doi: 10.1016/j.probengmech.2007.09.002.

Torabi, J., R. Ansari and R. Hassani. 2019. Numerical study on the thermal buckling analysis of CNT-reinforced composite plates with different shapes based on the higher-order shear deformation theory. European Journal of Mechanics-A/Solids, 73: 144-160. doi: 10.1016/j.euromechsol.2018.07.009.

Tung, H.V., 2017. Thermal buckling and postbuckling behavior of functionally graded carbonnanotube-reinforced composite plates resting on elastic foundations with tangential-edge restraints. Journal of Thermal Stresses 40(5): 641-663. doi: 10.1080/01495739.2016.1254577.

Yazdi, A.A., 2019. Nonlinear aeroelastic stability analysis of three-phase nano-composite plates. Mechanics Based Design of Structures and Machines: 1-16. doi: 10.1080/15397734.2019.1610436

Zarezadeh, E., V. Hosseini and A. Hadi. 2019. Torsional vibration of functionally graded nanorod under magnetic field supported by a generalized torsional foundation based on nonlocal elasticity theory. Mechanics Based Design of Structures and Machines: 1-16. doi: 10.1080/15397734.2019.1642766.

Zhu, J., H. Peng, F. Rodriguez-Macias, J. L. Margrave, V. N. Khabashesku, A. M. Imam, K. Lozano and E. V. Barrera. 2004. Reinforcing epoxy polymer composites through covalent integration of functionalized nanotubes. Advanced Functional Materials 14(7): 643-648. doi: 10.1002/adfm.200305162. 
Step 1

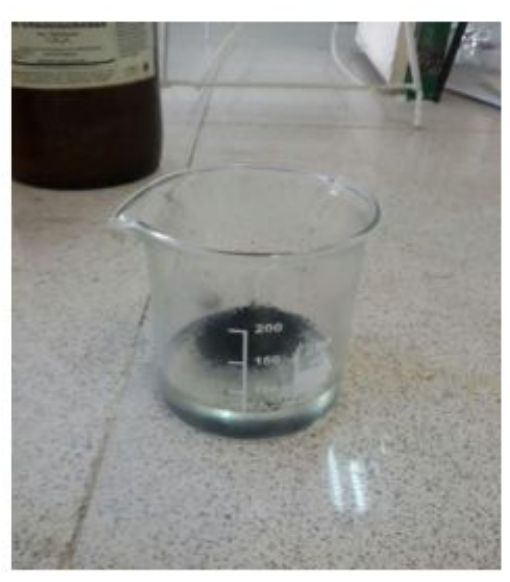

Step 4

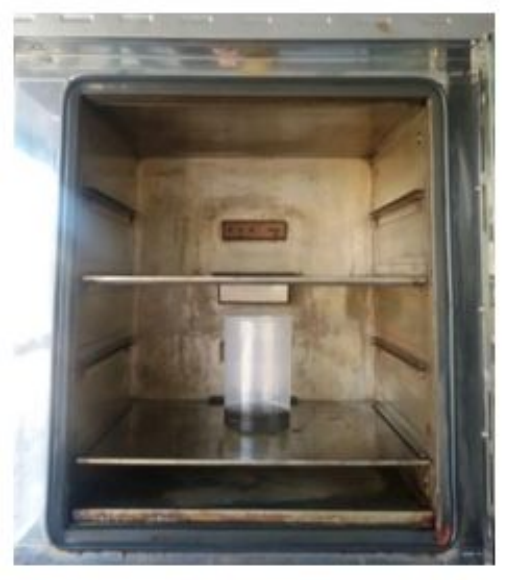

Step 2

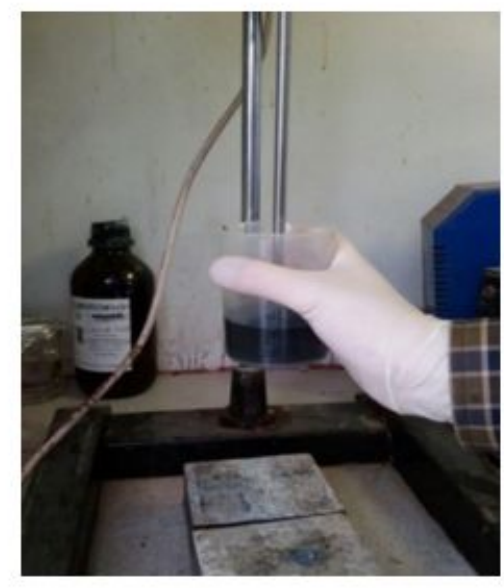

Step 5

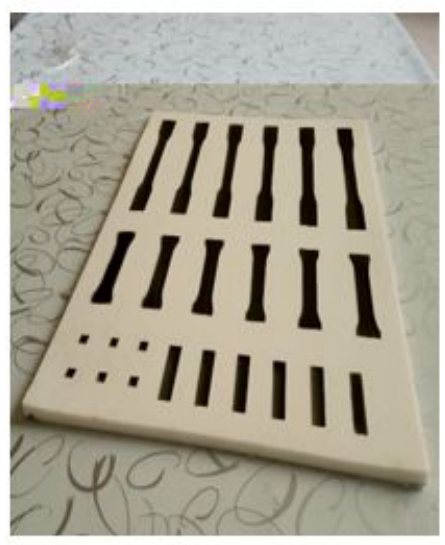

Step 3

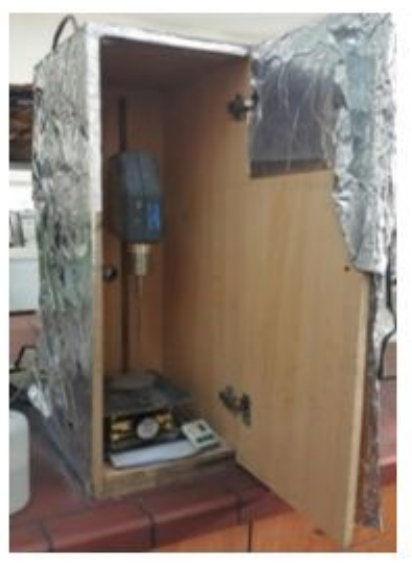

Step 6

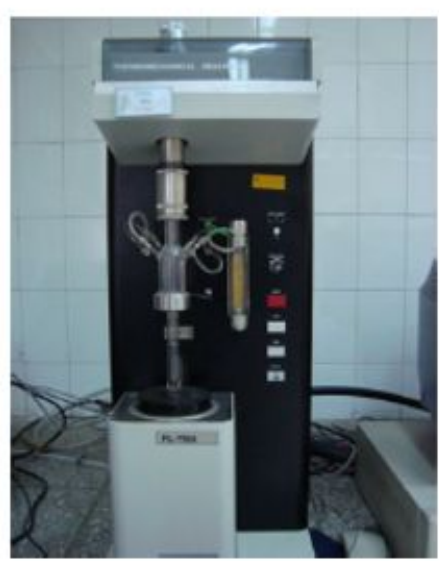

Fig. 1 Preparation of CNT/epoxy samples 


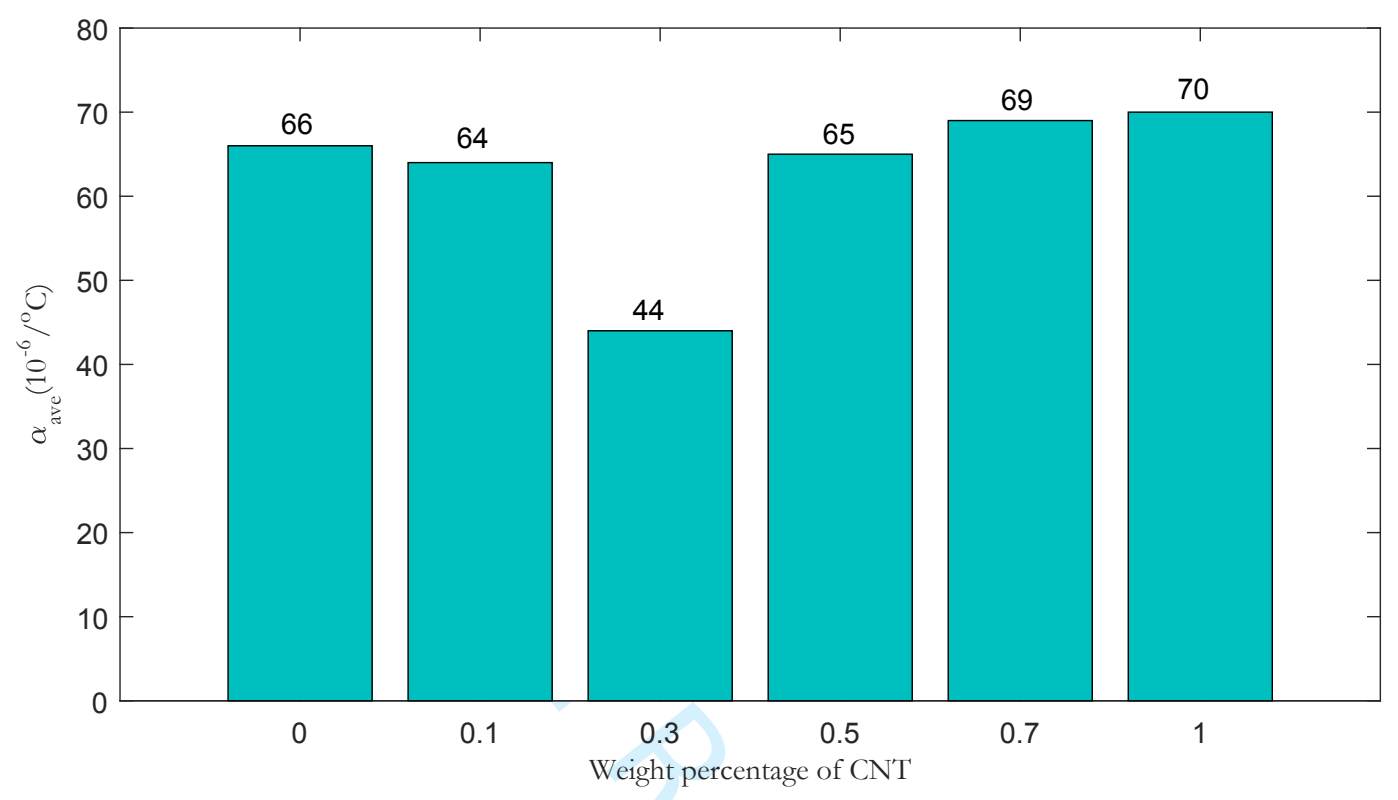

Fig. 2 CTE for nanocomposites with different wt.\% of MWCNTs. 

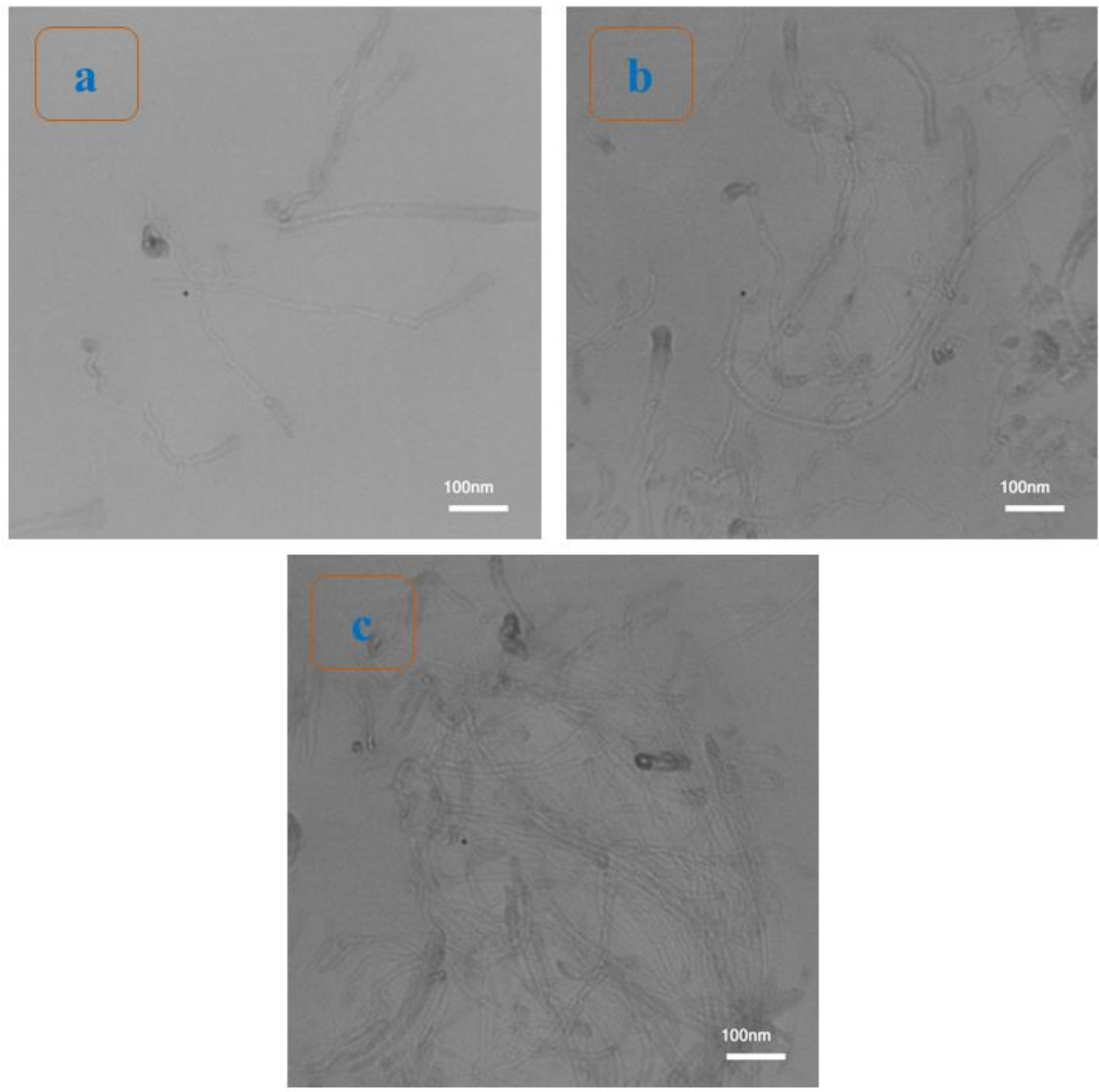

Fig. 3 The state of dispersion of MWCNTs in nanocomposite specimens with a) $0.3, b$ ) 0.5 and c) $1 \mathrm{wt} . \%$ of nanotubes obtained by TEM. 


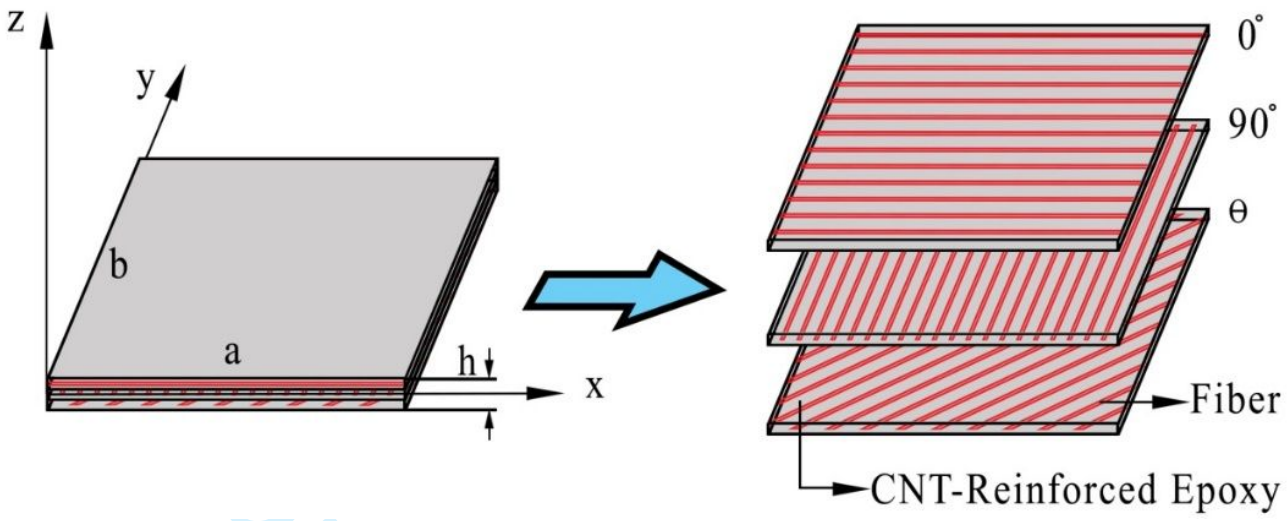

Fig. 4 Geometry of a rectangular CFRCNTEP plate

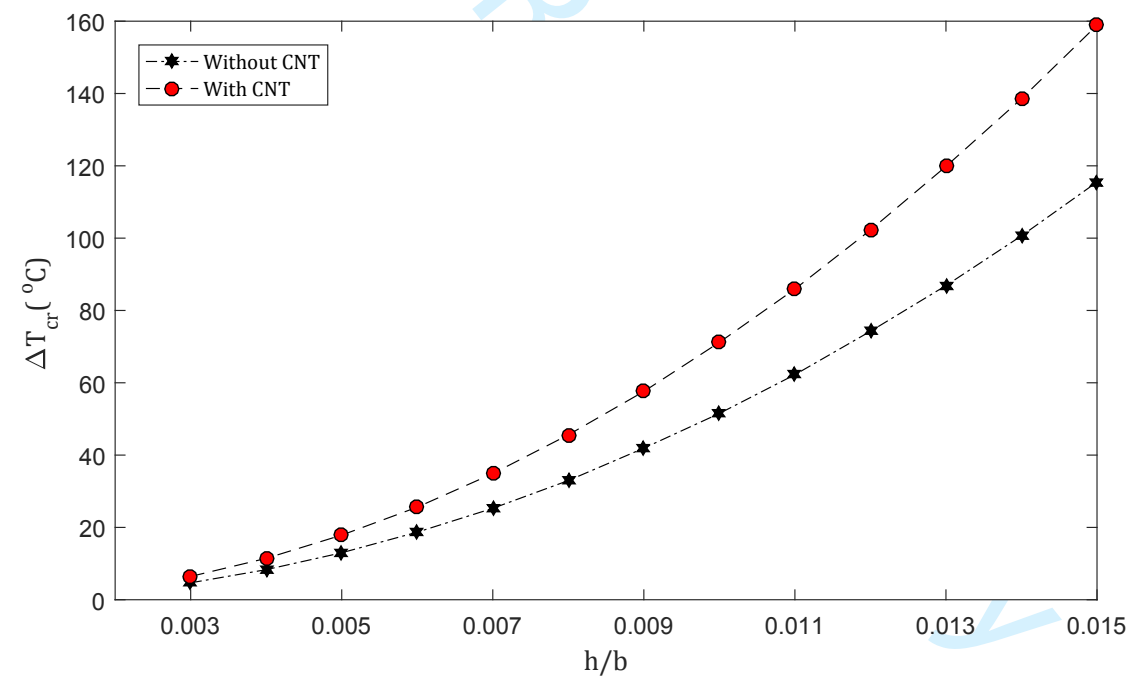

Fig. 5 The effect of MWCNT on critical buckling temperature of carbon-fiber-reinforced square plates with lamination scheme of $\left[30^{\square} /-45^{\square} / 90^{\natural}\right]_{s}$ and simply supported boundary conditions for different $h / b$ ratios 


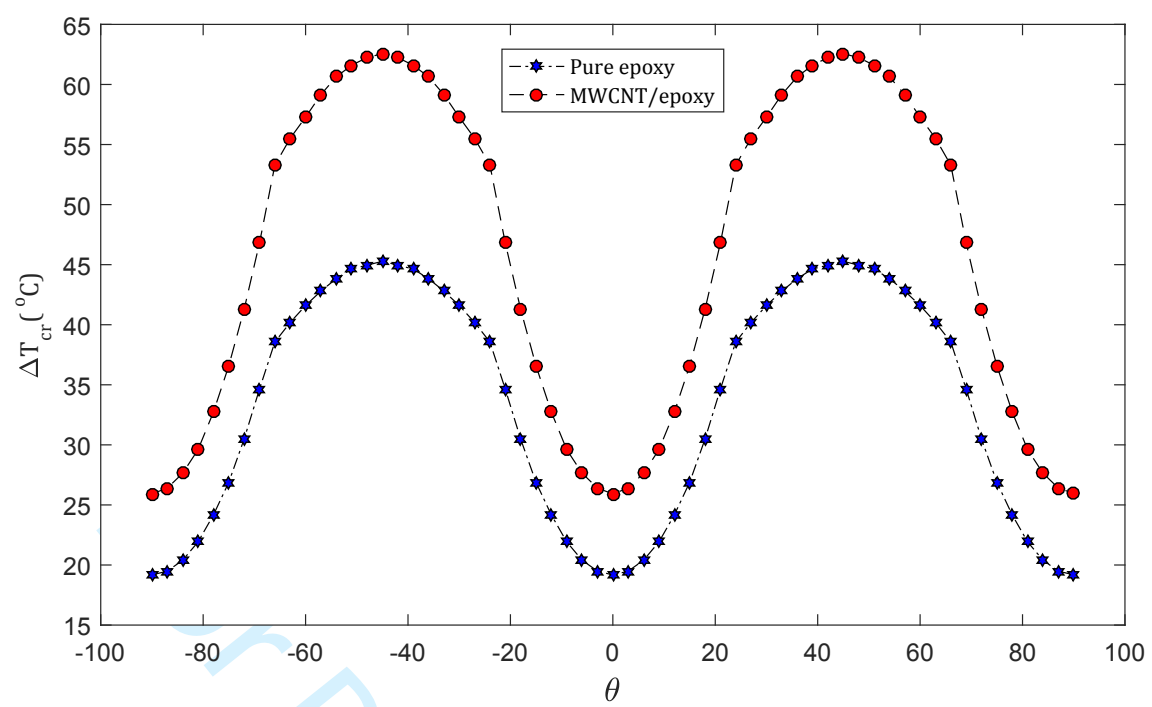

Fig. 6 The effect of CNTs on critical buckling temperature of $[\theta /-\theta]_{s}$ square plates for different lamination scheme $(h / b=0.01)$

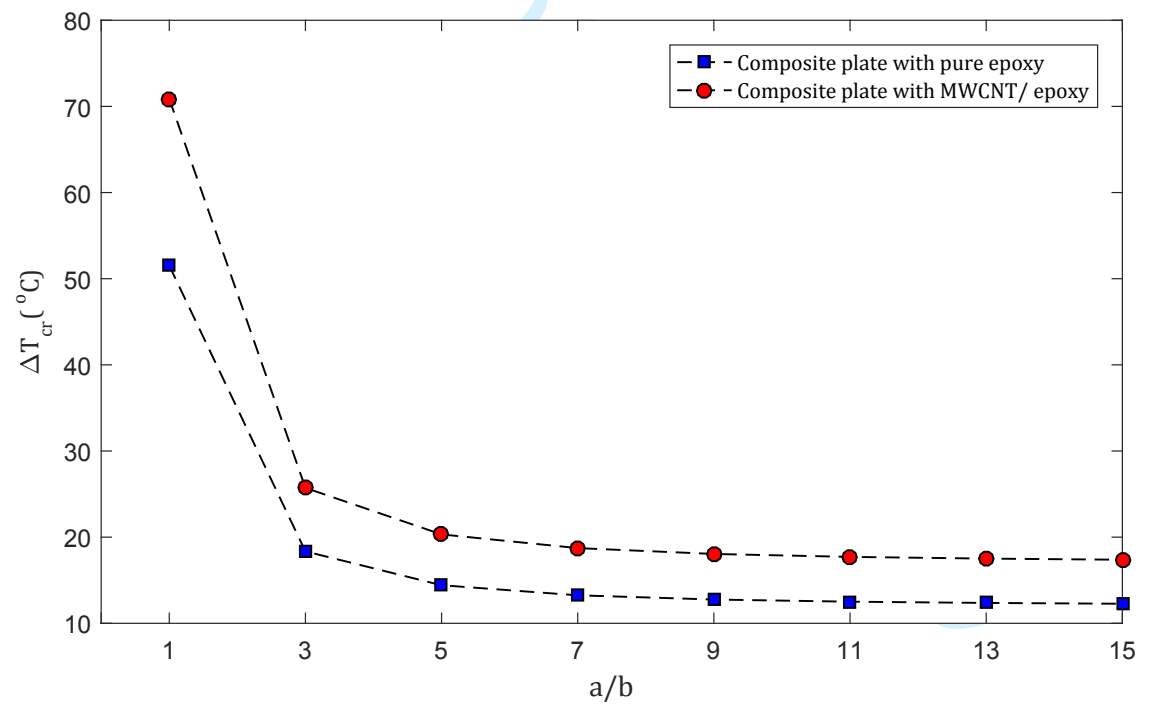

Fig. 7 The effect of CNTs on critical buckling temperature of rectangular plates with lamination scheme of $\left[30^{\square} /-45^{\square} / 90^{\square}\right]_{s}$ and simply supported boundary conditions against length-to-width ratio $(h / b=0.01)$ 


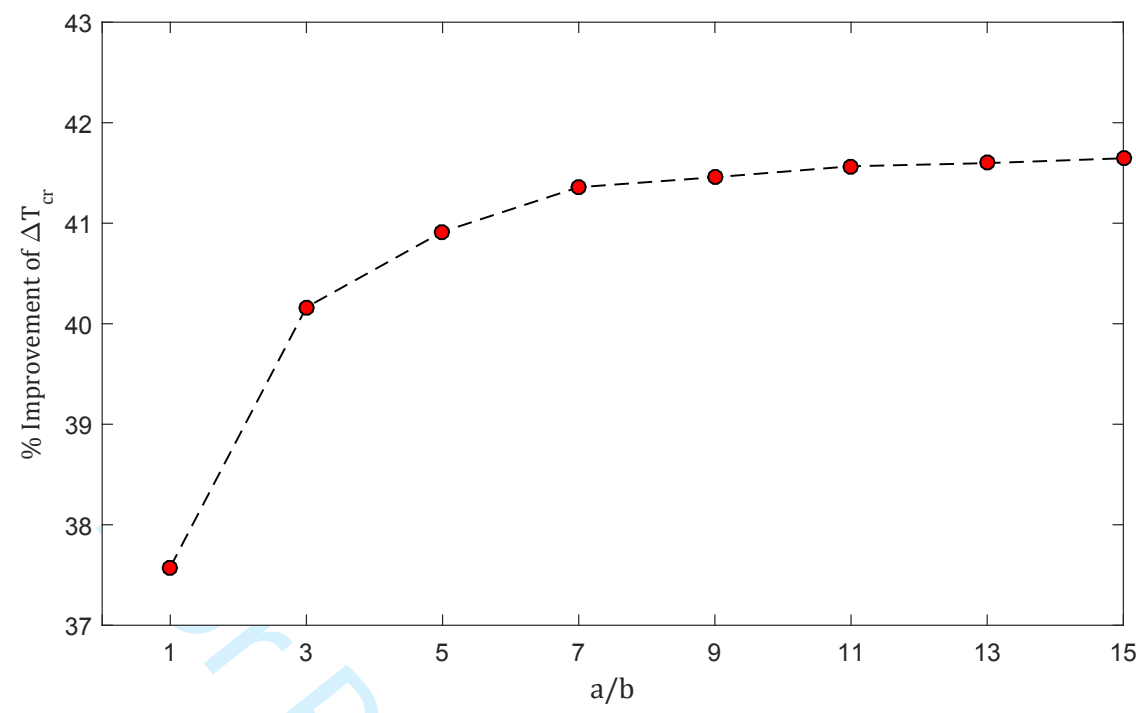

Fig. 8 The amount of increase of buckling temperature of simply supported $\left[30^{\natural} /-45^{\natural} / 90^{\natural}\right]_{s}$ rectangular plates by adding CNTs into the polymer matrix $(h / b=0.01)$ 
Table 1. Thermal expansion coefficient from the present TMA test and manufacturer's date sheet

\begin{tabular}{|c|c|c|c|c|}
\hline \multirow{3}{*}{ TMA test } & \multicolumn{4}{|c|}{ Thermal Expansion Coefficient $\left(\alpha \times 10^{-6}{ }^{0} C^{-1}\right)$} \\
\hline & \multicolumn{3}{|c|}{ manufacturer's date sheet } & \multirow{2}{*}{ TMA test } \\
\hline & $25^{\natural} C / 7 d$ & $50^{\natural} C / 15 h$ & $80^{\square} C / 8 h$ & \\
\hline $20-50$ & 97 & - & - & - \\
\hline $20-90$ & - & 71 & - & - \\
\hline $20-120$ & - & - & 71 & 66 \\
\hline
\end{tabular}

Table 2. Mean value of CTE $\left(\times 10^{6} /{ }^{\circ} \mathrm{C}\right)$ for experimental tests against different $\mathrm{CNT}$ weight percentages

\begin{tabular}{ccccccc}
\hline & \multicolumn{7}{c}{ wt $\%$ of CNTs } \\
\cline { 2 - 7 } & 0 & 0.1 & 0.3 & 0.5 & 0.7 & 1 \\
\hline Mean Value of CTE & 66 & 64 & 44 & 65 & 69 & 70 \\
\hline
\end{tabular}

Table 3. Material properties of the pure epoxy and CNT/epoxy nanocomposite adopted from different methods.

\begin{tabular}{|c|c|c|c|c|c|}
\hline \multirow{2}{*}{ Property } & \multirow{2}{*}{ Unit } & \multicolumn{2}{|c|}{ Pure Epoxy } & \multicolumn{2}{|c|}{ CNT-Reinforced Epoxy } \\
\hline & & Value & Method & Value & Method \\
\hline Young's Modulus & $G P a$ & 3.10 & Data Sheet & 3.38 & Theoretical Model \\
\hline CTE & $10^{-6} /{ }^{\circ} \mathrm{C}$ & 66 & Experiment & 44 & Experiment \\
\hline Poisson's Ratio & - & 0.35 & Data Sheet & 0.35 & Assumption \\
\hline
\end{tabular}


Table 4. Material properties of the carbon fibers

\begin{tabular}{ccc}
\hline Property & Unit & Value \\
\hline$E_{1}$ & $G P a$ & 225 \\
$E_{2}$ & $G P a$ & 15 \\
$G_{12}$ & $G P a$ & 15 \\
$v_{12}$ & - & 0.2 \\
$\alpha_{1}$ & $10^{-6} /{ }^{\circ} \mathrm{C}$ & -0.5 \\
$\alpha_{2}$ & $10^{-6} /{ }^{\circ} \mathrm{C}$ & 15 \\
\hline
\end{tabular}

Table 5. Material properties of CFREP and CFRCNTEP composites.

\begin{tabular}{ccccc}
\hline Property & Unit & CFREP Composite & CFRCNTEP Composite & Improvement (\%) \\
\hline$E_{1}$ & $G P a$ & 136.24 & 136.25 & 0.08 \\
$E_{2}$ & $G P a$ & 6.59 & 7.02 & 6.52 \\
$G_{12}$ & $G P a$ & 2.57 & 2.78 & 8.17 \\
$v_{12}$ & - & 0.35 & 0.35 & 0 \\
$\alpha_{1}$ & $10^{-6} /{ }^{\circ} \mathrm{C}$ & 0.105 & -0.059 & 156.19 \\
$\alpha_{2}$ & $10^{-6} /{ }^{\circ} \mathrm{C}$ & 44.553 & 32.716 & 26.57 \\
\hline
\end{tabular}

Table 6. Convergence and accuracy of the critical buckling temperature parameter $\left(\lambda_{T}=100 \alpha_{0} \Delta T_{c r}\right)$ of cross-ply $\left[0^{\square} / 90^{\natural}\right]_{s}$ rectangular plates for different boundary conditions $\left(a / b=1, h / b=0.01, \alpha_{0}=10^{-6} 1 /{ }^{\circ} C\right)$.

\begin{tabular}{cccccc}
\hline & \multicolumn{3}{c}{$N_{x}=N_{y}$} & \multirow{2}{*}{ Kant and Babu 2000 } \\
\cline { 2 - 5 } BCs & 9 & 11 & 13 & 17 & \\
\hline SSSS & 0.0992 & 0.0996 & 0.0996 & 0.0996 & 0.0997 \\
CCCC & 0.3355 & 0.3354 & 0.3354 & 0.3354 & 0.3352 \\
\hline
\end{tabular}


Table 7. The effect of MWCNT on critical buckling temperature of carbon-fiber-reinforced square plates with lamination scheme of $\left[30^{\square} /-45^{\square} / 90^{\natural}\right]_{s}$ and simply supported boundary conditions for different $h / b$ ratios

\begin{tabular}{cccc}
\hline$h / b$ & Pure Epoxy Matrix & MWCNT/Epoxy Matrix & Improvement $(\%)$ \\
\hline 0.003 & 4.68 & 6.44 & 37.61 \\
0.004 & 8.32 & 11.44 & 37.50 \\
0.005 & 12.99 & 17.87 & 37.57 \\
0.006 & 18.69 & 25.60 & 36.97 \\
0.007 & 25.28 & 34.88 & 37.97 \\
0.008 & 32.96 & 45.60 & 38.35 \\
0.009 & 41.92 & 57.60 & 37.40 \\
0.010 & 51.52 & 71.18 & 38.16 \\
0.011 & 62.24 & 85.92 & 38.04 \\
0.012 & 74.24 & 102.24 & 37.72 \\
0.013 & 86.88 & 119.84 & 37.93 \\
0.014 & 100.64 & 138.56 & 37.68 \\
0.015 & 115.52 & 158.88 & 37.53 \\
\hline
\end{tabular}

Table 8. The influence of CNTs on critical buckling temperature of $\left[30^{\natural} /-45^{\natural} / 90^{\natural}\right]_{s}$ plates for different boundary conditions $(a / b=1, h / b=0.01)$.

\begin{tabular}{cccc}
\hline Boundary Conditions & Epoxy Matrix & MWCNT/Epoxy Matrix & Improvement (\%) \\
\hline SSSS & 51.52 & $70.88^{`}$ & 37.58 \\
SCSC & 72.96 & 100.96 & 38.38 \\
CCCC & $116 . .66$ & 160.64 & 37.70 \\
\hline
\end{tabular}

